\title{
RANCANGAN SISTEM INFORMASI PENYEWAAN BUS DENGAN PENDEKATAN ELECTRONIC CUSTOMER RELATIONSHIP MANAGEMENT (E-CRM)
}

\author{
Wulandari $^{1}$, Pandu Dwi Putra Nugroho ${ }^{2}$, Farhan Ramadhan ${ }^{3}$ \\ 1,2,3 Fakultas Teknologi Informasi, Sistem Informasi, Universitas Budi Luhur, Jakarta, Indonesia \\ Email:Wulandari@budiluhur.ac.id ${ }^{1}$,1512501196@student.budiluhur.ac.id ${ }^{2}$, 1512502822@student.budiluhur.ac.id ${ }^{3}$
}

\begin{abstract}
Abstrak- Perkembangan teknologi yang semakin pesat memainkan peran penting dalam perusahaan, perusahaan berlomba-lomba menguasai pasar dan untuk meningkatkan pelayanan agar pelanggan tetap setia menggunakan barang dan jasa perusahaan. Dalam Penelitian ini perusahaan yang diteliti adalah perusahaan yang bergerak dalam bidang transportasi, melayani jasa angkutan darat baik penumpang maupun barang. Perusahaan tersebut mempunyai tagline "Joruney with Pleasure" yang memiliki arti dimana pelanggan yang memanfaatkan jasa layanan kami akan merasakan kenyamanan, pelayanan dan mendapatkan kesan positif selama perjalanan. Masalah yang dihadapi perusahaan saat ini adalah kesulitan dalam mendapatkan pelanggan baru, belum ada informasi penyewaan bus secara online dan testimoni dari pelanggan terhadap pelayanan perusahaan. Tujuan penulisan ini untuk mengenalkan lebih luas profile perusahaan kepada masyarakat dengan dibuatkan sistem berbasis web dan pemberian pelayanan terbaik untuk mendapatkan kepuasan dan loyalitas pelanggan menggunakan pendekatan Elektronik Customer Relationship Management (E-CRM). Dalam memodelkan kebutuhan sistem penulis menggunakan Unified Modelling Language (UML), database yang digunakan MYSQ1, untuk membuat aplikasi penulis menggunakan PHP dan pengujian sistem penulis menggunakan blackbox testing. Dengan dibangunya Elektronik Customer Relationship Management (E-CRM) ini diharapkan membantu perusahaan dalam meningkatkan pelayanan dan loyalitas pelanggan sehingga kedepanya terjalin hubungan baik dengan pelanggan. Dari hubungan baik antara perusahaan dan pelanggan perusahaan dapat lebih mudah mendapatkan pelanggan baru dan mempertahankan pelanggan lama.
\end{abstract}

Kata Kunci: E-CRM, Customer Relationship Management, Penyewaan Bus, Sistem Informasi, Penyewaan.

Abstract- The rapid development of technology plays an important role in the company, companies are competing to dominate the market and to improve services so that customers remain loyal in using the company's goods and services. In this study, the companies under study are companies engaged in the transportation sector, serving both passenger and freight land transportation services. The company has the tagline "Joruney with Pleasure" which means that customers who use our services will feel comfortable, service and get a positive impression during the trip. The problems faced by the company today are difficulties in getting new customers, there is no online bus rental information and customer testimonials about company services. The purpose of this paper is to introduce a broader company profile to the public by creating a web-based system and providing the best service to get customer satisfaction and loyalty using the Electronic Customer Relationship Management (E-CRM) approach. In modeling system requirements the author uses the Unified Modeling Language (UML), the database used by MYSQl, to make the author's application using PHP and the author's system testing using blackbox testing. With the development of Electronic Customer Relationship Management (E-CRM), it is expected to help companies improve customer service and loyalty so that in the future there will be good relationships with customers. From a good relationship between the company and the company's customers, it is easier to get new customers and retain old customers.

Keywords: E-CRM, Customer Relationship Management, Bus Rentals, Information Systems, Rentals.

\section{PENDAHULUAN}

Dalam era globalisasi dan lingkungan ekonomi yang cepat berubah diikuti dengan perkembangan teknologi informasi yang sangat pesat, dimana teknologi saat ini telah memainkan peran penting dalam persaingan bisnis. Kebanyakan perusahaan tidak hanya memilih untuk memuaskan kebutuhan pelanggan tetapi sudah membangun hubungan jangka panjang dengan pelanggan[1]. Peran pelanggan dalam dunia bisnis sangatlah vital [2], banyaknya pelanggan pada sebuah perusahaan dapat menjadi indikator keberhasilan perusahaan itu sendiri. demi mendapatkan keuntungan yang besar [3]. Banyak perusahaan yang berlomba-lomba untuk menguasai teknologi informasi, dengan harapan dapat menguasai pasar dan mendapatkan pelanggan yang setia [4]. selain itu kepuasan pelanggan adalah kunci perusahaan dalam mengambil langkah untuk mengelola pemasaran dan merupakan salah satu kunci perusahaan untuk menaikan pendapatan. Pelanggan yang puas akan melakukan repeat-order, pelanggan puas akan melakukan feedback atau timbal balik yang baik atau berbentuk masukan untuk perusahaan dalam menaikan kualitas pelayanan maupun produk dan pelanggan puas pun akan mengajak pelanggan baru untuk membeli produk atau jasa perusahaan[5].

Perusahaan yang diteliti adalah perusahaan yang bergerak dalam bidang transportasi, melayani jasa angkutan darat baik penumpang maupun barang. Perusahaan tersebut mempunyai tagline "Joruney with Pleasure" yang memiliki arti dimana pelanggan yang memanfaatkan jasa layanan kami akan merasakan kenyamanan, pelayanan dan mendapatkan 
kesan positif selama perjalanan. Saat ini perusahaan kesulitan dalam mendapatkan pelanggan baru dan belum memiliki kesulitan dalam mendapatkan pelanggan baru, belum ada informasi penyewaan bus secara online dan testimoni dari pelanggan terhadap pelayanan perusahaan. Penyewa merupakan pelanggan yang sedang menyewa suatu produk yang dimiliki suatu perusahaan[6]. Dalam hal ini penyewa selalu menuntut kepuasan atas kinerja perusahaan Selain itu perusahaan juga mengalami kendala dalam hal mempertahankan pelanggan dikarenakan belum adanya informasi tentang kepuasan maupun kepuasan pelanggan. Kondisi ini jelas mengharuskan manajemen perusahaan melakukan langkah baru untuk menjaga dan meningkatkan kepuasaan serta loyalitas pelanggan. Dengan masalah tersebut, perusahaan membutuhkan suatu metode manajemen untuk mengontrol hubungan perusahaan dengan pelanggan atau yang disebut Customer Relationship Management(CRM) [5]. Customer Relationship Management (CRM) adalah jenis manajemen yang secara khusus membahas teori mengenai penanganan hubungan antara perusahaan dengan pelanggannya, yang mana tujuannya untuk meningkatkan hubungan dengan tiap pelanggan demi mencapai pertumbuhan perusahaan yang sehat[7][8]. Selain itu CRM juga berkaitan dengan pelanggan dalam suatu perusahaan yang bertujuan untuk meningkatkan akses yang lebih cepat dan kualitas dari suatu proses bisnis yang melibatkan beberapa bidang yaitu bidang pemasaran (marketing), bidang pemesanan (order), dan pelayanan pelanggan. [9]

Penelitian yang dilakuka oleh H. Amiinnul Ummah, I. Sodikin, and J. Susetyo yaitu membangun sistem informasi yang akan memudahkan SukaKamera dalam melakukan pengolahan data dan pelanggan dalam melakukan pemesanan serta membangun hubungan komunikasi SukaKamera dengan pelanggan dengan metode customer relationship management. Saat melakukan pengembalian produk, pelanggan diharuskan untuk mengisi review dan rating[10].

Penelitian yamg dilakukan Luh Manik Sugiarni, Ni Pramana, Dian Nyoman Harini Puspita, Ni yaitu membangun sistem informasi untuk menarik pelanggan baru agar membeli produk perusahaan dan juga mempertahankan pelanggan lama agar tetap membantu proses pemasaran terhadap produk-produk perusahaan. Dengan penggunaan sistem management pelanggan menggunakan metode Customer Relationship Management (CRM). Tujuan dari sistem tersebut dapat menarik pelanggan baru dan mempertahankan pelanggan yang telah ada agar dapat membantu setiap proses pemasaran yang dilakukan oleh perusahaan[11].

\section{METODOLOGI PENELITIAN}

\subsection{Tahapan Penelitian}

Berikut ini merupakan Langkah - Langkah penelitian yang dilakukan penulis dalam kegiatan analisa dan perancangan pada perusahaan yang di tunjukan pada gambar 1 .

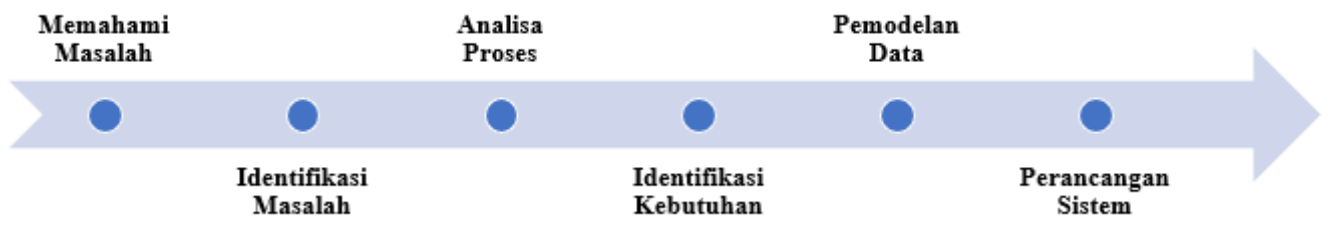

Gambar 1. Tahapan Penelitian

Penulis melakukan pengumpulan data agar memahami masalah yang ada, kemudian penulis melakukan identifikasi masalah dan penganalisaan proses bisnis sebelum melakukan identifikasi kebutuhan serta pemodelan data yang diakhiri dengan perancangan sistem.

\subsection{Metode Pengumpulan Data}

Dalam menyelesaikan masalah pada perusahaan, penulis menggunakan pendekatan dengan Elektronic Customer Relationship Management (CRM), maka penulis menggunakan beberapa metode pengumpulan data yaitu dengan cara:

a. Wawancara

Pengumpulan data dengan cara bertatap muka langsung dengan mengajukan beberapa pertanyaan mengenai proses bisnis yang sedang berjalan kepada bagian terkait.

b. Analisa Dokumen

Pengumpulan data dengan mencari infomrasi berdasarkan dokumen berjalan yang terkait agar diperoleh informasi yang akurat sebagai bahan kebutuhan sistem yang akan penulis buat.

c. Studi Pustaka 
Penulis melakukan studi kepustakaan dari beberapa buku dan referensi lain yang berkaitan dengan permasalahan yang sedang diamati, serta melakukan pencarian informasi tambahan dengan internet.

\section{HASIL DAN PEMBAHASAN}

\subsection{Proses Bisnis Berjalan}

Langkah-langkah atau tahapan yang terjadi di setiap proses bisnis yang sedang berjalan. Berikut proses bisnis yang ada pada perusahaan, yaitu:

a. Proses Penyewaan

Calon Penyewa mengajukan rencana penyewaan bus melalui telepon atau datang langsung ke kantor. Calon Penyewa mengisi data-data identitas diri dan menentukan tanggal dan tujuannya kepada bagian Administrasi perusahaan. Kemudian bagian Adminsitrasi mengecek ketersediaan bus bedasarkan tanggal keberangkatan yang sudah ditetapkan oleh calon penyewa, jika bus tersedia maka bagian Administrasi akan mengkonfirmasikan total harga pemesanan dan metode pembayaran, jika tidak maka bagian Administrasi akan memberitahukan bahwa bus tidak tersedia kepada penyewa. Lalu calon penyewa memilih metode pembayaran, jika memilih Down Payment (DP) maka calon penyewa harus membayar DP sebesar 30\% dari total harga penyewaan, jika memilih Lunas maka calon penyewa memberikan uang penyewaan sebesar total harga penyewaan dan akan dibuatkan bukti kwitansi pelunasan dari bagian Administrasi perusahaan.

b. Pembayaran DP

Penyewa dapat melakukan pembayaran DP. Apabila penyewa membayar secara transfer, maka calon penyewa akan melakukan transfer uang DP sebesar 30\% dari total harga penyewaan ke rekening perusahaan. Setelah itu, penyewa mengirimkan email yang berisi foto bukti transfer yang menyatakan bahwa telah melakukan transfer ke email perusahaan. Jika pembayaran secara tunai, penyewa langsung bayar ditempat. Setelah membayar DP, maka bagian Administrasi akan mencatat ke form reservasi dan membuat kwitansi pembayaran DP.

c. Proses Pelunasan

Penyewa datang ke bagian administrasi. Jika penyewa membawa bukti kwitansi maka penyewa memberikan bukti kwitansi tersebut ke bagian Administrasi, jika tidak maka penyewa hanya cukup memberitahukan nomor pesanan ke bagian administrasi. Lalu bagian Administrasi mencari form reservasi bedasarkan nomor pesanan penyewa tersebut. Lalu penyewa membayar uang pelunasan DP. Setelah itu Administrasi membuat dan menstampel bukti kwitansi pelunasan dan memberikannya ke penyewa.

d. Proses Pembatalan

Jika terjadi pembatalan pemesanan dari pihak penyewa kurang dari 3 hari sebelum tanggal penggunaan bus, maka dikenakan biaya pembatalan sebesar 50\% dari total harga pembayaran. Jika pembatalan lebih dari 3 hari maka penyewa dikenakan biaya pembatalan sebesar 30\%, dan Jika pembatalan dari pihak penyewa pada tanggal penggunaan maka akan dikenakan biaya pembatalan sebesar $100 \%$ dari total harga pembayaran.

e. Proses Pembuatan Surat Jalan (SJ)

Sebelum pemberangkatan bus ke tempat tujuan sewa, Kondektur akan meminta surat jalan dan biaya jalan kepada bagian Administrasi. Kemudian bagian Administrasi membuat Surat Jalan (SJ) dan menyiapkan biaya perjalanan. Kemudian bagian Administrasi memberi SJ dan biaya perjalanan kepada Kondektur. Setelah menerima, Kondektur akan memberikan informasi kepada Supir untuk menjemput ke tempat tujuan sewa.

f. Proses Pengembalian BUS

Setelah Kondektur menerima Surat Jalan (SJ) dan biaya, maka bagian Administrasi akan memberitahu berapa lama waktu penyewaan tersebut dan lokasi pengembalian penyewa. Apabila penyewa melebih waktu penyewaan yang telah ditentukan, maka penyewa diwajibkan membayar biaya tambahan.

g. Proses Pembuatan Laporan

Berdasarkan buku reservasi pemesanan yang didapat dari pemesanan bus, setiap bulannya bagian Administrasi membuat laporan pendapatan untuk diserahkan kepada Direktur Utama perusahaan. 


\subsection{Activity Diagram Sistem Usulan}

Activity Diagram sistem usulan pada perusahaan ditunjukan pada gambar 2,3,4.

a. Activity Diagram Penyewaan

Activity Diagram usulan penyewaan bus ditunjukan pada gambar 2.

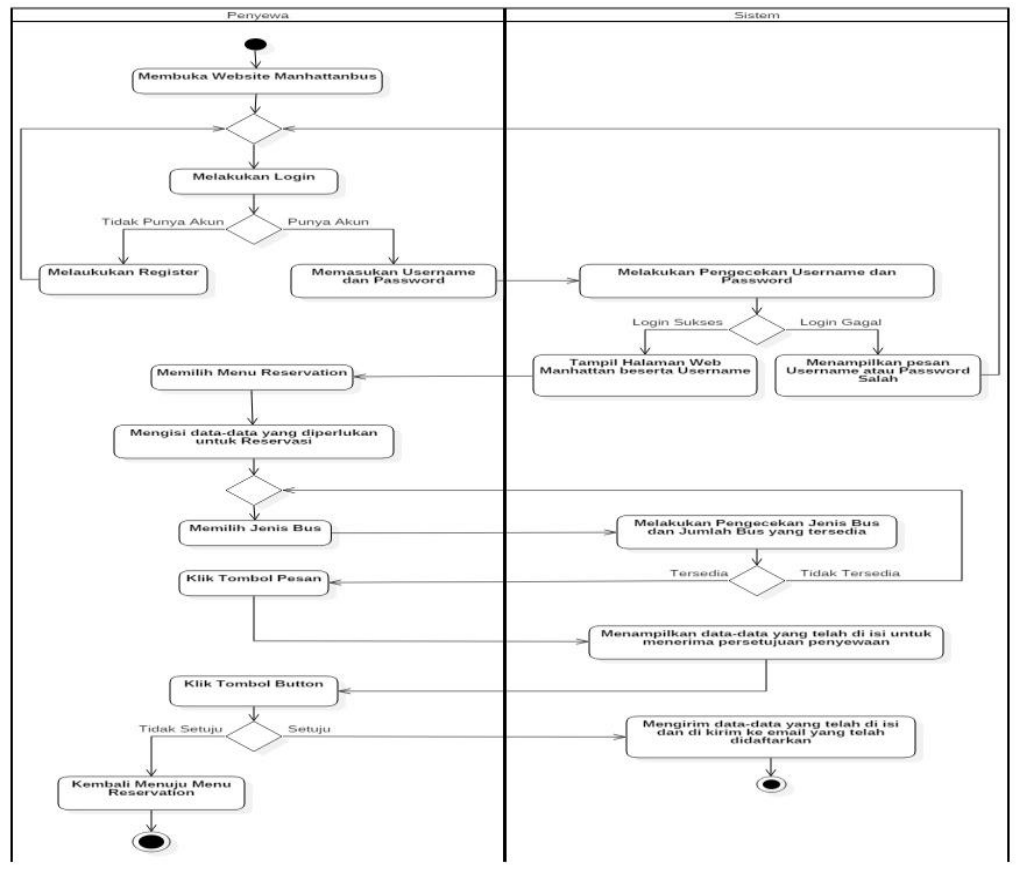

Gambar 2. Activity Diagram Penyewaan

b. Activity Diagram Pembayaran Lunas

Activity Diagram pelunasan pembayaran ditunjukan pada gambar 3.

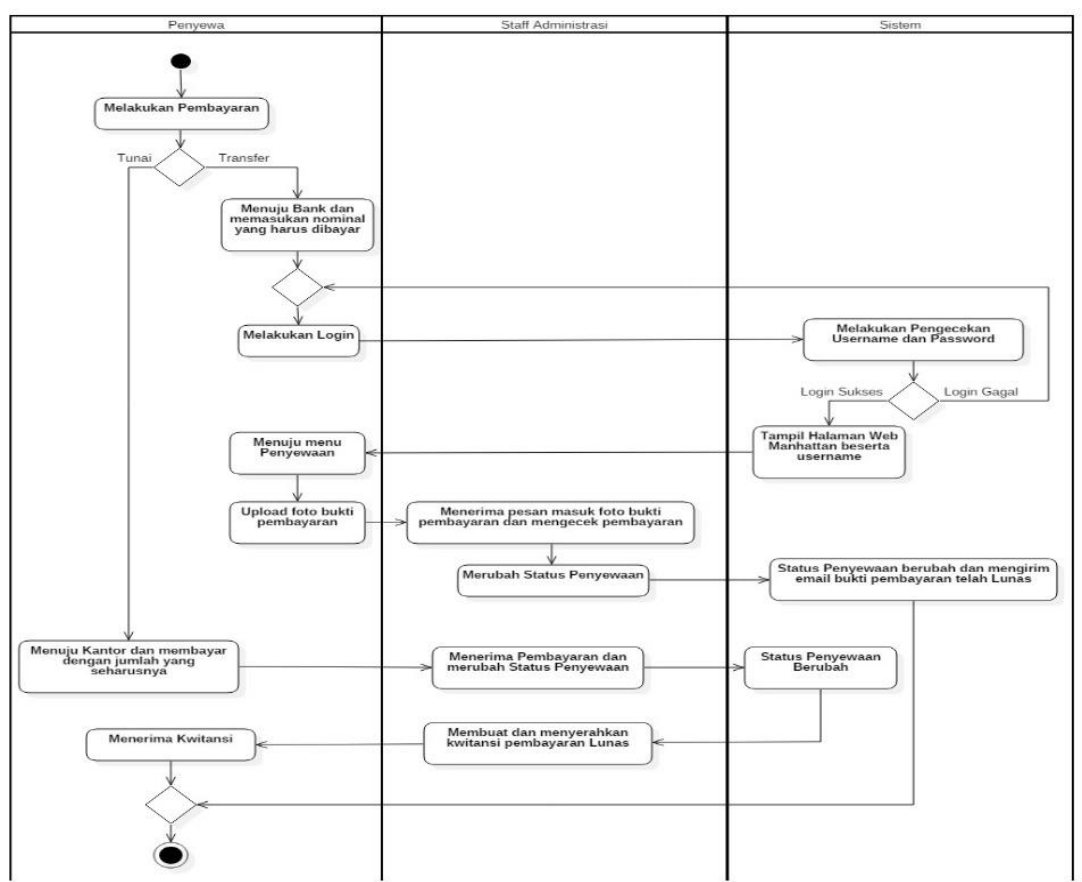

Gambar 3. Activity Diagram Pembayaran Lunas 
available online at http://jom.fti.budiluhur.ac.id/index.php/IDEALIS/index

\subsection{Use case Diagram}

Use Case diagram adalah merupakan gambaran interaksi antara sistem dengan pemakai (user). Dengan kata lain use case diagram dengan nyata menguraikan siapa yang akan menggunakan sistem dan dengan cara apa pemakaidapat saling berhubungan dengan sistem [12]. Gambar use case diagram transaksi ditunjukan pada gambar 5 .

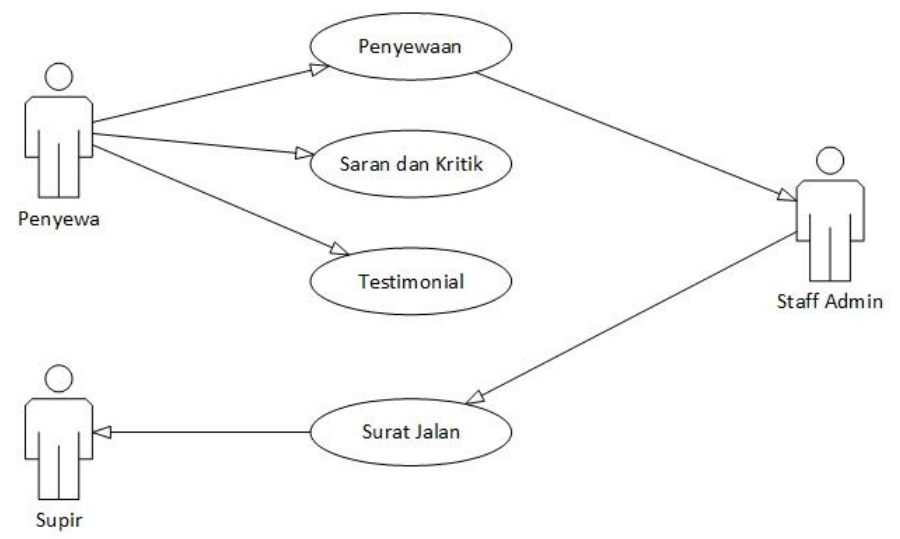

Gambar 5. Use case Diagram Transaksi

\subsection{Logical Record Structure(LRS)}

Logical Record Structure(LRS) merupakan representasi dari struktur record-record pada tabel-tabel yang terbentuk dari hasil antar himpunan entitas [13]. LRS ditunjukan pada gambar 6.

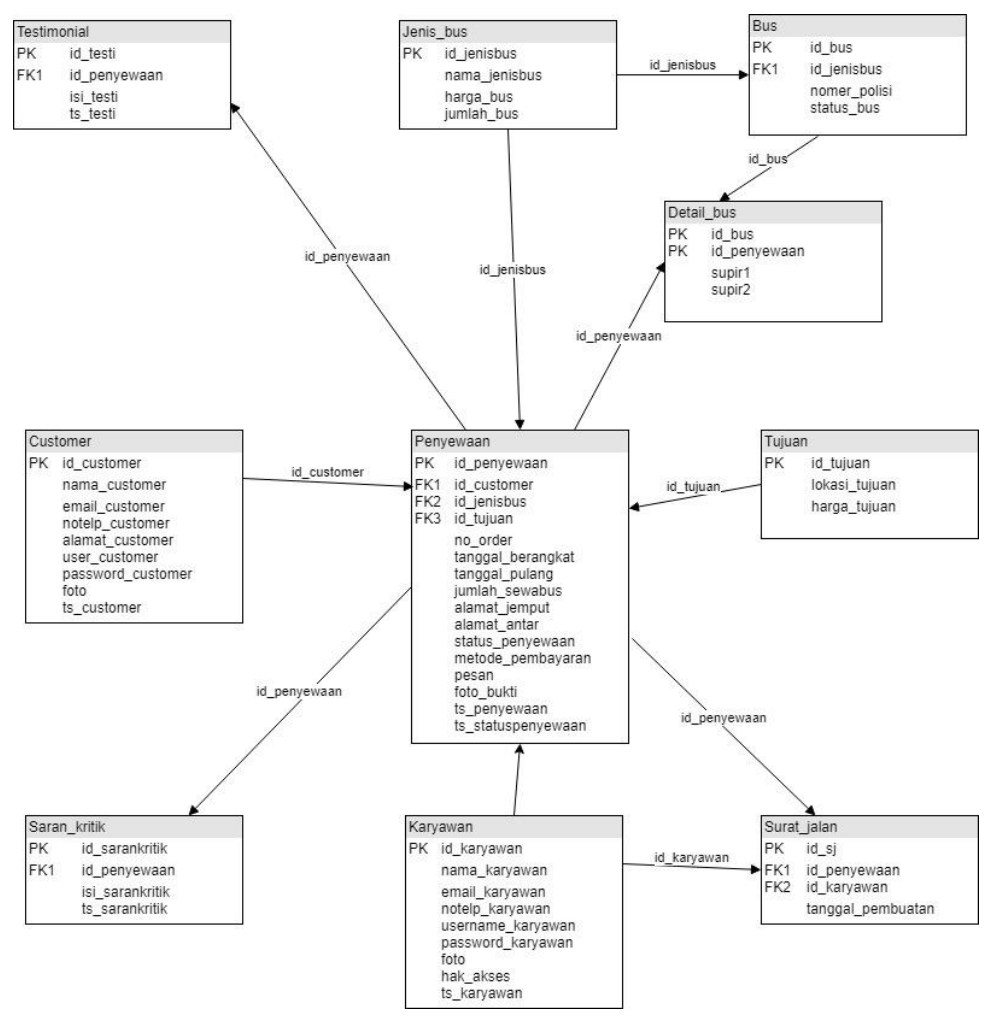

Gambar 6. Logical Record Structure

\subsection{Desain GUI}

Sistem antarmuka antara pengguna dan komputer yang ditampilkan dalam bentuk grafis seperti gambar, icon, bentuk, dan lain-lain [14]. Desain GUI perusahaan adalah sebagai berikut ini:

a. Struktur Menu front End 
available online at http://jom.fti.budiluhur.ac.id/index.php/IDEALIS/index

Struktur tampilan menu front End pada perusahaan dengan konsep Electronic Customer Relationship Management (E-CRM ditunjukan pada gambar 7.

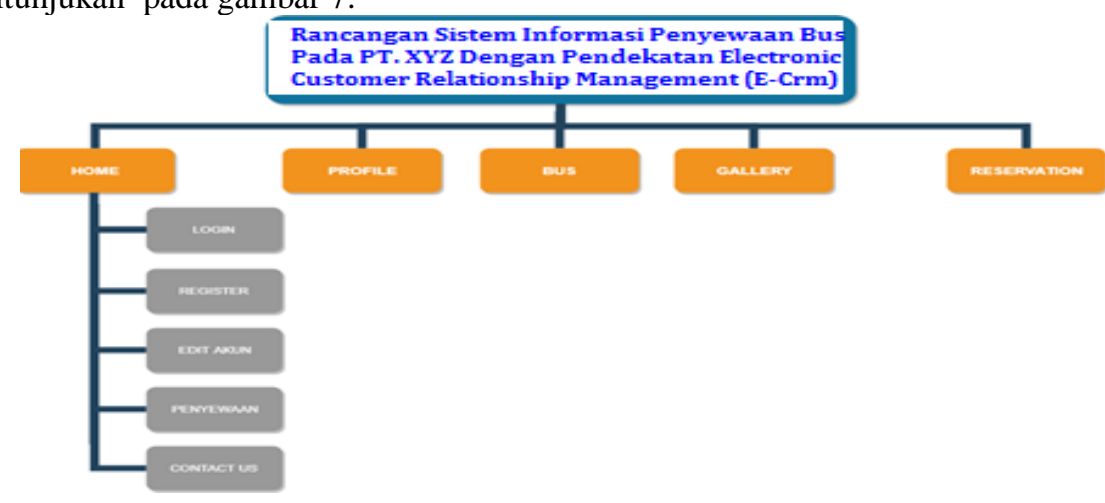

b. Struktur Menu Back End

Gambar 7. Struktur Menu Front End

Struktur tampilan menu back End pada perusahaan dengan konsep Electronic Customer Relationship Management (E-CRM) ditunjukan pada gambar 8.

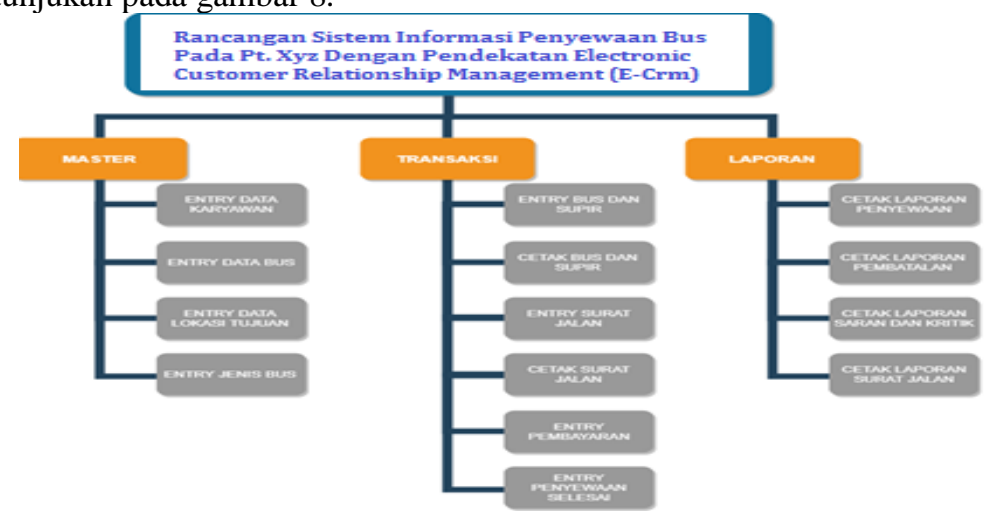

c. Rancangan Layar

Gambar 8. Struktur Menu Front End

1. Rancangan layar Front End

Rancangan layar Front End pada perusahaan ditunjukan pada gambar 9.

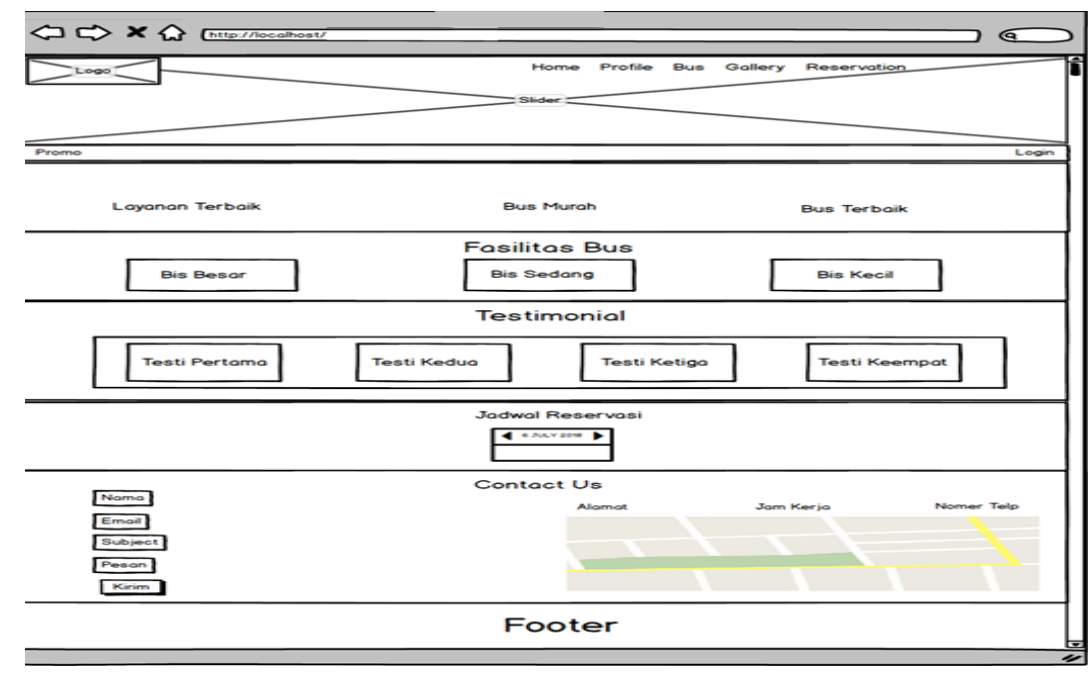

Gambar 9. Struktur Menu Front End 
2. Rancangan layar Back End

Rancangan layar Back End ditunjukan pada gambar 10.

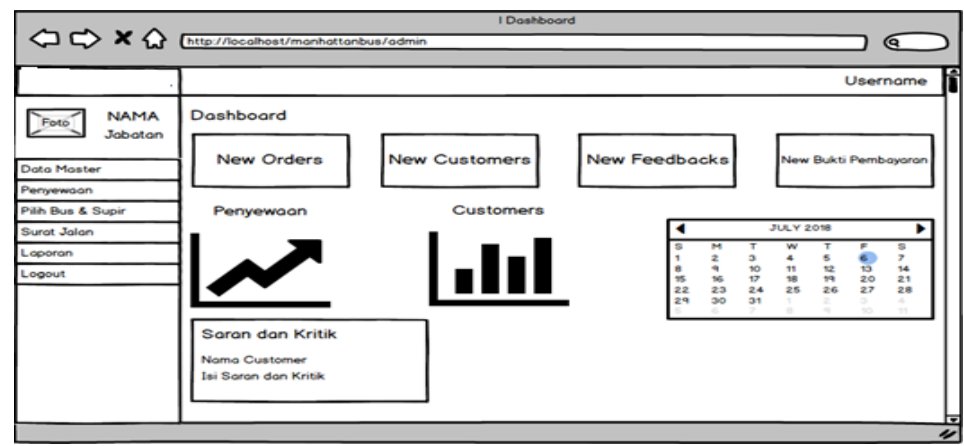

Gambar 10. Struktur Menu Back End

3. Rancangan layar Transaksi Reservasi/Pemesanan

Rancangan layar transaksi pemesanan/reservasi ditunjukan pada gambar 11 .

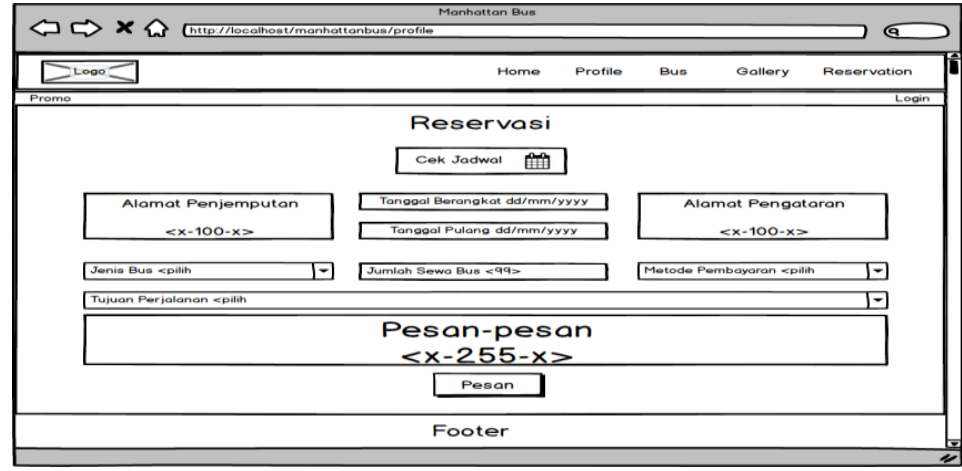

Gambar 11. Rancangan layar Transaksi Reservasi/Pemesanan

\section{d. Sequence Diagram}

Sequence Diagram menggambarkan kelakuan objek pada use case dengan mendeskripsikan waktu hidup objek dan pesan yang dikirimkan dan diterima antar objek[15]. Berikut ini merupakan beberapa sequence Diagram usulan pada perusahaan:

1. Sequence Diagram Master data karyawan Sequence diagram master data karyawan ditunjukan pada gambar 12.

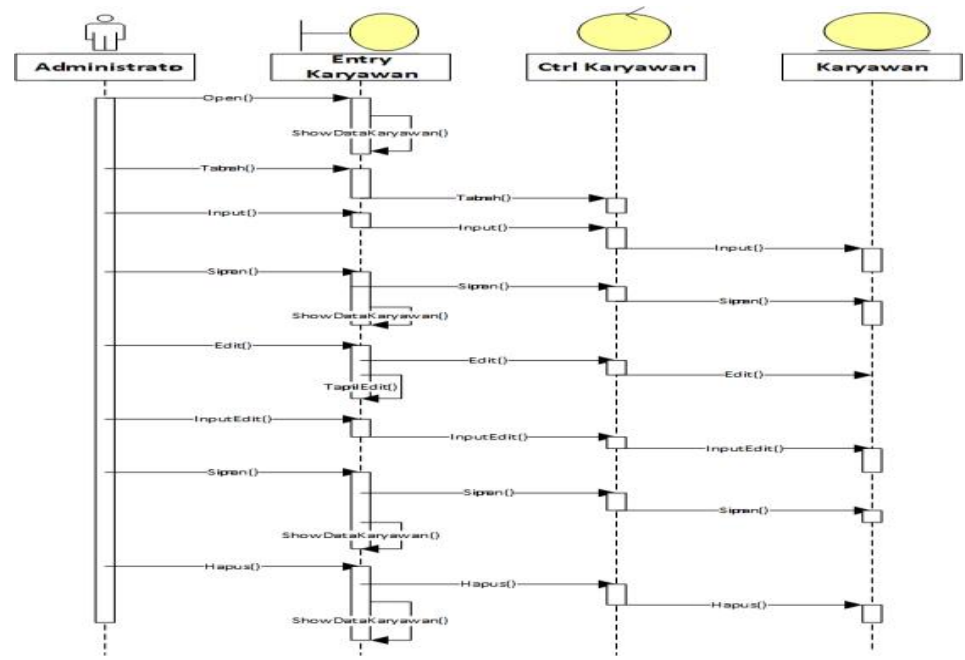

Gambar 12. Sequence diagram Master Data Karyawan 


\section{Halaman 1-10}

available online at http://jom.fti.budiluhur.ac.id/index.php/IDEALIS/index

2. Sequence Diagram Tansaksi penyewaan/reservasi

Sequence diagram transaksi penyewaan/reservasi pada perusahaan ditunjukan pada gambar 13 .

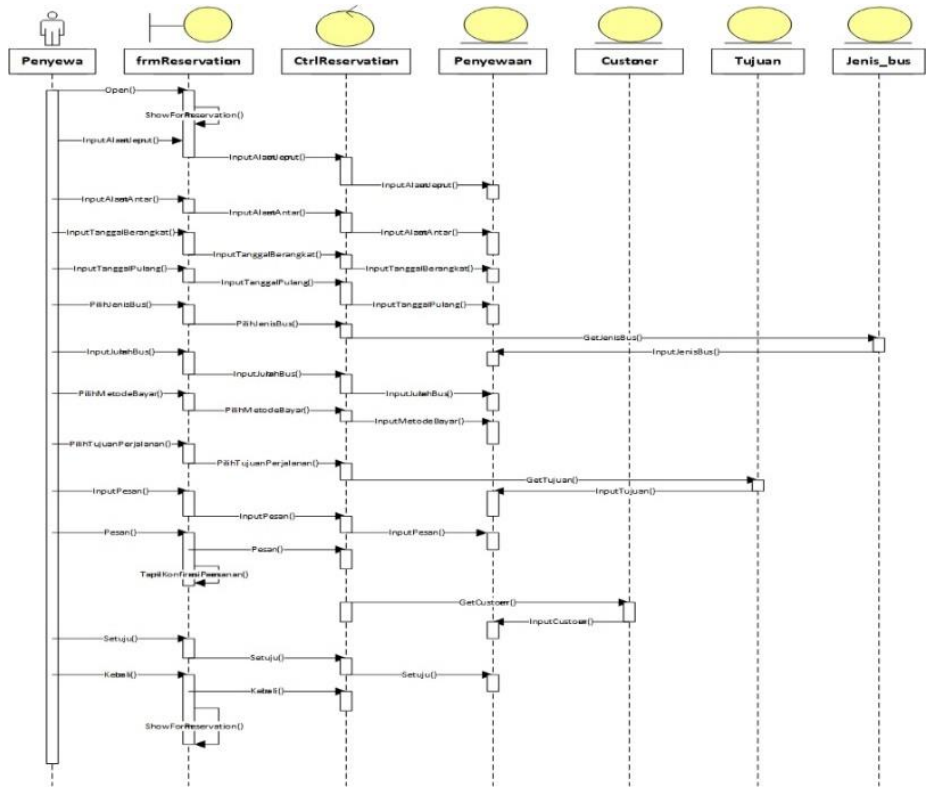

Gambar 13. Sequence diagram transaksi penyewaan

3. Sequence Diagram Laporan

Sequence diagram Laporan penyewaan ditunjukan pada gambar 14.

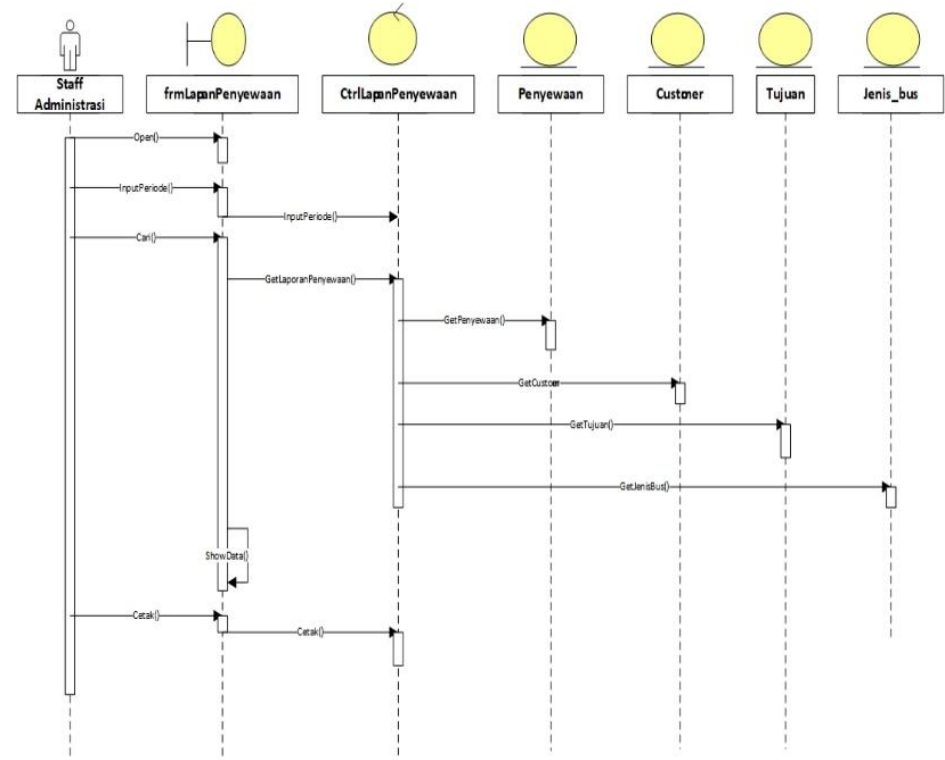

Gambar 14. Sequence diagram laporan

\subsection{Pengujian}

Pengujian sistem menggunakan Blacbox Testing yaitu dilakukan dengan memberikan input pada program, dari inputan tersebut dapat dilihat apakah program yang dibuat terdapat error dan isian yang masih kosong akan memberikan pesan agar field di isi lengkap. Pengujian blackbox testing menu reservasi pada PT. XYZ ditunjukan pada tabel 1. 
Tabel 1. Blackbox Testing Menu Reservasi

\begin{tabular}{|c|c|c|c|}
\hline No & Sekenario pengujian & Hasil Yang Diharapkan & Kesimpulan \\
\hline 1 & $\begin{array}{l}\text { Jika terdapat data yang masih kosong } \\
\text { dan di Klik tombol "Pesan" } \\
\text { Test Case: }\end{array}$ & $\begin{array}{l}\text { Sistem Akan menolak dan menampilkan } \\
\text { Pesan "Please fill out this field" } \\
\text { Hasil pengujian: }\end{array}$ & Valid \\
\hline 2. & $\begin{array}{l}\text { Jika isian form reservasi Sudah lengkap } \\
\text { dan diklik tombol "Pesan" } \\
\text { Test Case: }\end{array}$ & $\begin{array}{l}\text { Sistem Akan menampilkan Pesan "Data } \\
\text { Berhasil Disimpan" } \\
\text { Hasil pengujian: }\end{array}$ & Valid \\
\hline
\end{tabular}

Dari pengujian yang sudah dilakukan, tidak terdapat eror sehingga sistem dapat digunakan sebagaimana mestinya.

\section{KESIMPULAN}

\subsection{KESIMPULAN}

Berdasarkan analisa dan penelitian yang dilakukan penulis, maka dapat ditarik kesimpulan sebagai berikut:

h. Dengan dibuatnya sistem Electronic Customer Relationship Management (E-CRM), informasi perusahaan dan website yang telah di buat akan menjembatani informasi yang dibutuhkan oleh masyarakat luas.

i. Fitur testimoni/feedback didalam sistem yang telah diusulkan digunakan untuk menerima dan menyimpan komplain yang diberikan oleh pelanggan, sehingga perusahaan dapat mengevaluasi dan dapat digunakan pertimbangan dalam pengambilan keputusan.

j. Dengan adanya informasi ketersediaan bus, pelanggan dengan mudah mengetaui jumlah bus yang ready/ada. Sehingga mempermudah pelanggan dalam melakukan pemesanan/reservasi.

\subsection{SARAN}

a. Agar sistem ini dengan berjalan dengan lancar, diharapkan adanya proses pelatihan dan kerjasama yang baik pada semua pihak staf perusahaan yang terkait.

b. Sistem yang dibuat diharapkan dapat dikembangkan lagi untuk penelitian berikutnya, agar pelayanan dan loyalitas pelanggan lebih maksimal. Contoh ada fitur Chat Online pada website tersebut. 
INDONESIA JOURNAL INFORMATION SYSTEM (IDEALIS)

Volume 4, Nomor 1, Januari 2021

ISSN 2684-7280 (online)

Halaman 1-10

available online at http://jom.fti.budiluhur.ac.id/index.php/IDEALIS/index

\section{DAFTAR PUSTAKA}

[1] H. Zhafar And B. D. Andah, "Penerapan Electronic Customer Relationship Management Terhadap Upaya Peningkatan Kepuasan Dan Loyalitas Pelanggan Ahass Sinar Makmur Sentosa Pada Divisi Perawatan Motor ( H2 )," J. Idealis, Vol. Vol 1 No 1, Pp. 461-467, 2018.

[2] B. Wicaksono And Samsinar, "Electronic Customer Relationship Management ( E-Crm ) Dalam Peningkatan Pelayanan Dan Loyalitas Pasien Kiropraktik ( Studi Kasus : Puri Chiropractic )," Idealis, Pp. 87-93, 2019.

[3] H. Patrie Et Al., "Penerapan Electronic Customer Relationship Management ( E-Crm ) Pada The Media Hotel And Tower," J. Idealis, Vol. Vol .1 No., Pp. 269-277, 2018.

[4] S. Aulia Sari And W. Usino, “Upaya Peningkatan Pelayanan Dan Loyalitas Customer,” Idealis, Vol. Vol 1 No 3, Pp. 94-101, 2018.

[5] M. Almira, P. Aji, And B. D. Andah, "Pengaruh Electronic Customer Relationship Management Dalam Upaya Meningkatkan Penjualan Pada Pt. Wiraswasta Gemilang Indonesia," Vol. Vol 1 No., Pp. 323-327, 2018.

[6] I. Lestari And H. Irawan, "Analisis Dan Desain Electronic Customer Relationship Management ( E- Crm ) Berbasis Web Guna Membina Serta Meningkatkan Loyalitas Penyewa Studi Kasus : Pt. Sari Indah Lestari ( Sil ) - Mall Cbd Ciledug,” Vol. 10, No. $2,2017$.

[7] A. J. Kundre, I. Wisnubadhra, T. Suselo, T. Informatika, P. Pascasarjana, And T. Industri, "Penerapan Customer Relationship Management Dengan Dukungan Teknologi Informasi Pada Po. Chelsy," Semnas Teknomedia, Vol. Issn 2302-, 2013.

[8] R. Handayani, "Penerapan Customer Relationship Management (Crm) Sistem Rawat Jalan Pada Rumah Sakit Ernaldi Bahar Provinsi Sumatera Selatan," 2014

[9] A. Heru Danardatu, "Pengenalan Customer Relationship Management (Crm).Pdf.” Ilmukomputer.Com, Pp. 1-4, 2003.

[10] H. Amiinnul Ummah, I. Sodikin, And J. Susetyo, "Perancangan Sistem Informasi Rental \& Inventaris Alat Multimedia Berbasis Webmenggunakan Metode Customer Relationship Management," Rekavasi, Vol. 7, No. 2, 2019.

[11] N. Luh Manik Sugiarni, D. Pramana, And N. Nyoman Harini Puspita, "Implementasi Crm ( Customer Relationship Management ) Pada Sistem Informasi Travel X Berbasis Web."

[12] Sholiq, Analisa Dan Perancangan Berorientasi Objekno Title. Yogyakarta: Graha Ilmu, 2010.

[13] A. Sukmaindrayana And R. Sidik, "Aplikasi Grosir Pada Toko Rsidik Bungursari Tasikmalaya," Idealis, Vol. 4, No. 2, 2017.

[14] D. Martin, “18 Konsep Dasar Graphic User Interface (Gui)! Desainer Wajib Tahu,” 2020. [Online]. Available: Https://Www.Techfor.Id/18Konsep-Dasar-Graphic-User-Interface-Gui-Desainer-Wajib-Tahu/\#: :Text=Desainer Wajib Tahu,-3\&Text=Graphic User Interface (Gui) Adalah,Bentuk\%2c Dan Lain-Lain.

[15] A. Hendini, "Pemodelan Uml Sistem Informasi Monitoring Penjualan Dan Stokbarang (Studi Kasus: Distro Zhezha Pontianak)," J. Khatulistiwa Inform., Vol. Iv, No 2, No. 2, Pp. 107-116, 2016. 